\title{
Saponins from Swartzia langsdorffii: Biological Activities
}

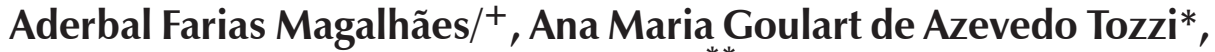 Celira Caparica Santos, Deborah Regina Serrano ${ }^{* *}$, Eliana Maria Zanotti-Magalhães**, Eva Gonçalves Magalhães, Luiz Augusto Magalhães**}

Departamento de Química Orgânica, Instituto de Química *Departamento de Botânica **Departamento de Parasitologia, Instituto de Biologia, Universidade Estadual de Campinas, Caixa Postal 6154, 13083-970 Campinas, SP, Brasil

The presence of saponins and the molluscicidal activity of the roots, leaves, seeds and fruits of Swartzia langsdorffii Raddi (Leguminosae) against Biomphalaria glabrata adults and eggs were investigated. The roots, seeds and fruits were macerated in $95 \%$ ethanol. These extracts exerted a significant molluscicidal activity against $\mathrm{B}$. glabrata, up to a dilution of $100 \mathrm{mg} / \mathrm{l}$. Four mixtures $\left(\mathrm{A}_{2}, \mathrm{~B}_{2}, \mathrm{C}\right.$ and $\left.\mathrm{D}\right)$ of triterpenoid oleanane type saponins were chromatographically isolated from the seed and fruit extracts. Two known saponins (1 and 2) were identified as $\beta$ D-glucopyranosyl-[ $\alpha$-L-rhamnopyranosyl- $(1 \rightarrow 3)$ - $\beta$-D-glucuronopyranosyl-( $1 \rightarrow 3)]$-3 $\beta$-hydroxyolean-12-ene-28-

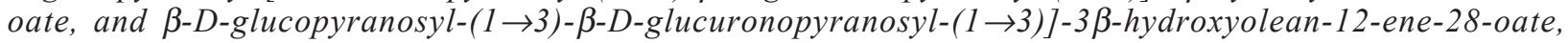
respectively. These two saponins were present in all the mixtures, together with other triterpenoid oleane type saponins, which were shown to be less polar, by reversed-phase HPLC. The saponin identifications were based on spectral evidence, including ${ }^{1}{ }^{H-}{ }^{1} H$ two-dimensional correlation spectroscopy, nuclear Overhauser and exchange spectroscopy, heteronuclear multiple quantum coherence, and heteronuclear multiple-bond connectivity experiments. The toxicity of $\mathrm{S}$. langsdorffii saponins to non-target organisms was prescreened by the brine shrimp lethality test.

Key words: Swartzia langsdorffii - Leguminosae - chemotaxonomy - saponins - molluscicidal activity - schistosomiasis Artemia salina

The aquatic gastropod mollusk Biomphalaria glabrata (Say, 1818) is the main intermediate host of schistosomiasis in South America. People acquire the parasite when they make contact with water containing infected snails; for example when extracting sand from river bottoms, fishing, washing animals, etc., in infested waters. The search for Brazilian native plants having molluscicidal properties to combat $B$. glabrata (adults and eggs) is of special importance since these may be less expensive than synthetic compounds. It is also important that the activity be located in the regenerating parts of the plant such as leaves and fruits (Clark et al. 1997). Due to their semi-transparency, the eggs of B. glabrata represent a suitable material for in vivo observation. The egg-masses contain a batch of about 30 fertilized eggs, each measuring approximately $100 \mu \mathrm{m}$ in diameter. The embryo reaches the blastula stage between 10 to $23 \mathrm{~h}$ after the eggs are laid (Kawano et al. 1992).

The molluscicidal activity of plants from the genus Swartzia has already been reported (Borel et al. 1987). The fruits of Swartzia madagascariensis Desvaux. (now Bobgunnia madagascariensis Desv. J. H. Kirkbride; Kirkbride \& Wiersema 1997) have been used to control populations of snail hosts of schistosomiasis in natural

${ }^{+}$Corresponding author. Fax: +55-19-3788.2332. E-mail: aderbal@iqm.unicamp.br

Contract/grant sponsor Capes. Scholarship awarded to CC Santos.

Contract/grant sponsor Fapesp. Financial support and scholarship awarded to DR Serrano

Received 24 January 2003

Accepted 3 June 2003 pools in Tanzania (Suter et al. 1986), since 1939. Phytochemical investigation of the dried fruits of $B$. madagascariensis gave triterpenoid saponins, which were shown to be responsible for the high molluscicidal activity of the fruits against B. glabrata (Borel \& Hostettmann 1987). The methanol extract $(400 \mu \mathrm{g} / \mathrm{ml})$ of S. simplex (Sw.) Spreng leaves also exhibited molluscicidal activity against B. glabrata snails (Borel et al. 1987).

S. langsdorffii Raddi [Synonyms: Mimosa pulchra Vell., Swartzia brasiliensis Vogel and Tounatea langsdorffii (Raddi) Kuntze] is a native Brazilian perennial tree (Mansano \& Tozzi 1999).

The present paper reports the isolation and identification of mixtures of olean-12-ene-type triterpenoid saponins found in the fruit and seed extracts of $S$. langsdorffii. As detailed spectral data for saponins $\mathbf{1}$ and 2 (Borel et al. 1987) are not available, these are presented here. The molluscicidal activity of root, leaf, fruit and seed extracts of $S$. langsdorffii against adult and egg-snail $B$. glabrata was investigated. The extracts were also submitted to the lethality test against Artemia salina.

\section{MATERIALS AND METHODS}

General procedure - Thin layer chromatography (TLC) was performed on Silica gel $60 F_{254} \mathrm{Al}$ sheets (Merck). ${ }^{1} \mathrm{H}-\mathrm{NMR}$ spectra were measured on a Varian Inova-500 (Palo Alto, CA, US) spectrometer at $500 \mathrm{MHz}$ or Varian Gemini-300 spectrometer at $300 \mathrm{MHz}:{ }^{13} \mathrm{C}-\mathrm{NMR}$ with the Gemini-300 at $75.45 \mathrm{MHz} .{ }^{1} \mathrm{H}$ and ${ }^{13} \mathrm{C}$ NMR spectra were recorded in pyridine- $d_{5}$ or $\mathrm{CD}_{3} \mathrm{OD}$ solutions. Chemical shifts are given in ppm and referenced to the solvent signal. Electron Spray Impact-Mass Spectra (ESI-MS) and Mass Spectra-Mass Spectra (MS/MS) experiments were performed using a $Q$-TOF Micromass (Wythenshawe, 
Manchester, UK) negative electron spray mass spectrometer. Reversed phase HPLC analysis was made using a Hewlett Packard HP 1090 series II/M (Wilmingston, DE, US) liquid chromatograph with a Waters $C$ 18 Nova-Pack column $(3.9 \times 150 \times 4 \mathrm{~mm})$. Detection was with a Hewlett Packard photodiode array detector mode, at room temperature. The mobile phase used for HPLC experiments was acetonitrile $\left(\mathrm{CH}_{3} \mathrm{CN}\right)$ and water in a gradient system changing from 5 to $95 \%$ of $\mathrm{CH}_{3} \mathrm{CN}$ in 30 $\mathrm{min}$. The samples were injected through a fixed loop (10 $\mu \mathrm{l}$ ), and were monitored for $30 \mathrm{~min}$, at a flow of $0.6 \mathrm{ml} / \mathrm{min}$. The solvents were filtered and degassed before each analysis; the water was distilled and degassed having a conductivity of $18.2 \mathrm{~m} \varpi$. All samples were dissolved in mobile phase and filtered through a Millex ${ }^{\circledR}$ filter. The presence of saponins in the HPLC/UV chromatograms of Mixtures $A-D$ were determined by their UV spectra, at a wavelength of $206 \mathrm{~nm}$, which were consistent with saponins UV spectra (Hostettmann \& Wolfender 1997).

Plant material - Vouchers of the specimen: Leguminosae Papilionoideae, S. langsdorffii Raddi. Brazil, São Paulo, Campinas, cultivated at Fazenda Santa Elisa, Monjolinho, collected in 22/03/97, by AMGA Tozzi, CC Santos \& JC Galvão 97-54 (UEC) were deposited at the herbarium of the Botany Department of Campinas State University (Unicamp), Campinas, SP, Brazil.

Preparation of plant extracts - Known weights of fresh and dry plant samples were exhaustively macerated with $95 \%$ ethanol at room temperature. The mixtures were filtered and the solvent removed under vacuum in a rotary evaporator. From the crude extracts, stock solutions $(1000 \mu \mathrm{g} / \mathrm{l})$ were freshly prepared in distilled water and different dilutions ranging from 10 to $100 \mathrm{mg} / \mathrm{ml}$, as well as controls, were prepared.

Bioassay - The lethality test against $A$. salina was performed by the method of McLaughlin et al. (1998). For the blank test, no lethality was observed (Table II).

Saponin test - The persistent foam test in diluted acid solution (Table III) was used to investigate the presence of saponins (Schenkel et al. 1999).

Test for molluscicidal activity toward adults - B. glabrata (melanic) snails - The test was made according to Hostettmann et al. (1997). The criterion for mortality determination was lack of movement when gently prodded. The data were analyzed by the Probit method (Finney 1962) and expressed as the $\mathrm{LC}_{50}$ (Table IV). Extracts that caused no mortality at $100 \mathrm{mg} / \mathrm{ml}$ were not investigated further.

Test for molluscicidal activity toward eggs - The test was carried out as previously reported by Okazaki et al. (1996) in the Parasitology Department of the Biology Institute, Unicamp.

The data were analyzed by the Probit method (Finney 1962) and expressed as the $\mathrm{LC}_{50}$ (Table IV). Extracts that caused no mortality at $100 \mathrm{mg} / \mathrm{ml}$ were not investigated further.

\section{Saponin mixtures}

Extraction I - One dried ground fruit or the seeds of one fruit were successively washed with petroleum ether, dichloromethane and chloroform to remove apolar compounds. The remaining solid was then macerated in ethanol, the solvent was removed and the amorphous brown solid was partially soluble in $95 \%$ ethanol. After filtration, the brown solid (Mixtures $A_{1}$ and $B_{l}$, fruit and seeds respectively) was submitted to the brine shrimp lethality test. The solution was concentrated furnishing a solid that was redissolved in methanol. The saponins were precipitated by the addition of diethyl ether.

The saponin precipitate isolated from the fruit was further purified by preparative thin layer chromatography developed with butanol and water (1:1), resulting in an amorphous pale brown solid (Mixture $A_{2}, 20 \mathrm{mg}$ ). This solid was shown to be rich in saponins, by the persistent foam test, and by the analysis of NMR spectra (Table V).

The saponin precipitate from the seeds (Mixture $B_{2}$, $30 \mathrm{mg}$ ) was analyzed by reversed-phase HPLC and by NMR spectra (Table VI).

Extraction II - Seed saponins isolated by partition between butanol and water - Fresh seeds from one fruit $(6.4 \mathrm{~g})$ were macerated in $95 \%$ ethanol. The solvent was removed, and resulted in a brown gum $(2 \mathrm{~g})$ that was washed with hexane. The hexane extract was removed and the remaining solid (1.36 g) was partitioned between butanol and water (1:1). The organic phase was separated and the butanol was removed. The crude mixture was rich in saponins (65 mg), and was analyzed by reversed-phase HPLC, and was further purified by preparative thin layer chromatography with dichloromethane: $\mathrm{MeOH}$ (93:7), giving a white solid (Mixture $C, 21.5 \mathrm{mg}$ ) containing saponins $\mathbf{1}$ and $\mathbf{2}, \mathrm{R}_{\mathrm{f}} 0.0$. The Mixture $C$ was also analyzed by reversed-phase HPLC (retention times, $1.4 \mathrm{~min}$ and 1.7 min) and by NMR spectra (Tables V-VIII).

Mixture D - Saponins isolated from the aril - Nine seeds $(120.5 \mathrm{~g})$ were air-dried and had their arils separated $(24.1 \mathrm{~g})$. The arils were macerated in $95 \%$ ethanol, at room temperature. The solvent was then totally evaporated giving rise to a brown gum that was then redissolved in methanol. Diethyl ether was added, forming a white precipitate, which was separated. The solid was further partitioned between butanol and water (1:1). The organic phase was separated and the butanol removed. After adding diethyl ether, the crude mixture was purified, resulting in a pale yellow solid (Mixture D, $1.3 \mathrm{~g}$ ), which was analyzed by reversed-phase HPLC (retention times $1.4 \mathrm{~min} ; 1.7 \mathrm{~min}$ and $14.2 \mathrm{~min}$ ) and by NMR spectra (Table VI).

$\beta$-D-glucopyranosyl-[ $\alpha$-L-rhamnopyranosyl- $(1 \rightarrow 3)-\beta$ D-glucuronopyranosyl-( $(1 \rightarrow 3)]$-3 $\beta$-hydroxyolean-12-ene28-oate (1) ESI-MS: $m / z 939$ [M-H] $]^{+}, m / z 777$ [M-H-162]',

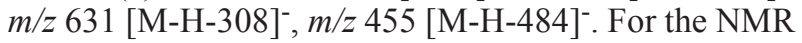
spectral data of the sugar moieties (see Table VII).

$\beta$-D-glucopyranosyl- $(1 \rightarrow 3)-\mathrm{O}-\beta$-D-glucuronopyranosyl-( $1 \rightarrow 3)]-3 \beta$-hydroxyolean-12-ene-28-oate (2). ESI-MS: $m / z 793$ [M-H] $]^{-}, m / z 631$ [M-H-162]', $m / z 455$ [M$\mathrm{H}-338]^{-}, m / z 455$ [M-H-484]. For the NMR spectral data of the sugar moieties (see Table VIII).

\section{RESULTS}

Bioassays - The occurrence of saponin in the leaf, root, seed and fruit extracts was detected by the persistent foam test in diluted acid solution (Table I). The 
molluscicidal activities against $B$. glabrata (adults and eggs) are shown in Table VI, which includes the results obtained with the saponin Mixtures $B_{2}$ (seed saponins) and $D$ (aril saponins). The developmental stages of the egg-masses have been followed and photographed (Fig. 1). Table II shows the activities of Mixtures $A_{1}, A_{2}, B_{2}$ and $D$ in the brine shrimp lethality test. The aril saponin mixture was inactive indicating low toxicity to non-target individuals.

HPLC results - Saponins $\mathbf{1}$ and $\mathbf{2}$ (retention times: 1.4 min, $1.7 \mathrm{~min}$ ) were present in all mixtures analyzed (Figs 24).

Mixture $B_{2}$ - Seeds saponins isolated by precipitation in diethyl ether - The chromatogram from the HPLC analysis of Mixture $B_{2}$ showed the presence of at least three other peaks attributed to less polar saponins (retention times: $12.2 \mathrm{~min}, 12.4 \mathrm{~min}$, and $14.2 \mathrm{~min}$ ).

Mixture C - Seed saponins isolated by partition between butanol and water - The HPLC analysis of Mixture $C$ showed two peaks (retention times: $1.4 \mathrm{~min}, 1.7$ min) corresponding to saponins $\mathbf{1}$ and $\mathbf{2}$.

Mixture D - Aril saponins isolated by precipitation in diethyl ether - This mixture was the more complex, however, the principal peaks (retention times $1.4 \mathrm{~min}, 1.7$ $\mathrm{min}$, and $14.2 \mathrm{~min}$ ), correspond to the same saponins already detected in Mixtures $B_{2}$ and $C$.

\section{TABLE I}

Lethal concentration $50 \%\left(\mathrm{LC}_{50}\right)$ in $24 \mathrm{~h}$ obtained for Artemia salina

\begin{tabular}{lc}
\hline Samples & $\mathrm{LC}_{50}(\mu \mathrm{g} / \mathrm{ml})$ \\
\hline Fruit mixture $A_{1}$ & 120.5 \\
Fruit saponin mixture $A_{2}$ & 5.36 \\
Seed mixture $B_{1}$ & 4.58 \\
Seed saponin mixture $B_{2}$ & $\mathrm{NT}$ \\
Seed saponin mixture $C$ & 3.59 \\
Aril saponin mixture $D$ & $>1000$ \\
\hline
\end{tabular}

TABLE II

Persistent foam test to detect saponins

\begin{tabular}{lc}
\hline Samples & Saponins \\
\hline Stalk $^{a}$ (EtOH extract) & - \\
Leaves $^{a}$ (EtOH extract) & - \\
Roots $^{a}$ (MeOH extract) & - \\
Fruits $^{a}$ (MeOH extract) & + \\
Seeds $^{a}$ (EtOH extract) & + \\
Fruit saponin mixture $A_{2}{ }^{b}$ & + \\
Seed mixture $B_{1}{ }^{b}$ & - \\
Seed saponin mixture $B_{2}{ }^{b}$ & + \\
Seed saponin mixture $C^{b}$ & + \\
Aril saponin mixture $D^{b}$ & +
\end{tabular}

$a$ :crude extract; $b$ : isolated saponin mixture; + : positive $=$ persistent foam observed; - : negative $=$ no foam observed

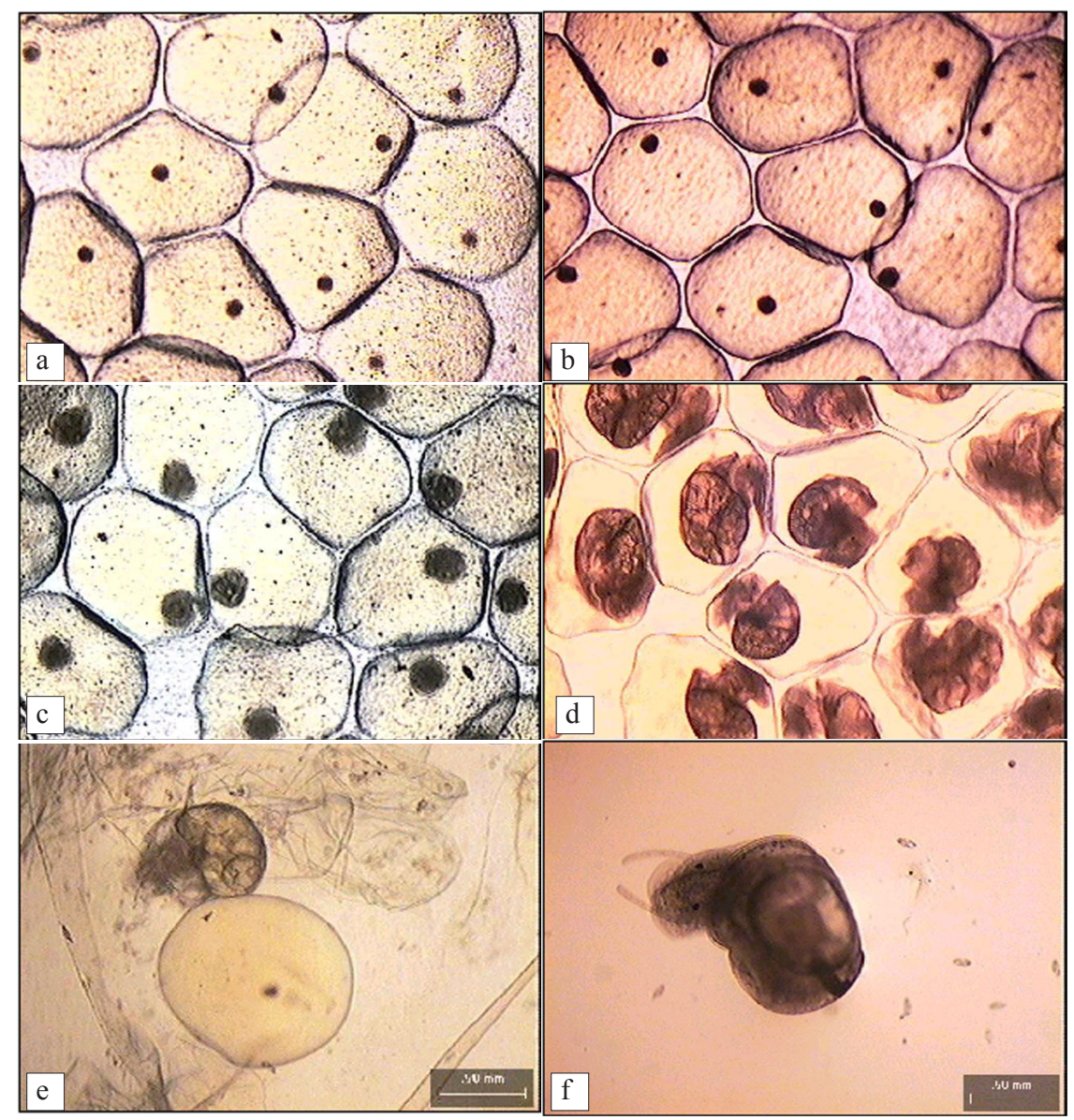

Fig. 1: embryo development observed for an egg-mass - a: egg-mass freshly laid (25X); b: blastula stage $24 \mathrm{~h}$ (25X); c: egg-mass on the 3rd day $(25 \mathrm{X})$; d: egg-mass on the 7 th day $(25 \mathrm{X})$; e: eclosion $(25 \mathrm{X})$; f: mollusk, 15 th day $(25 \mathrm{X})$ 

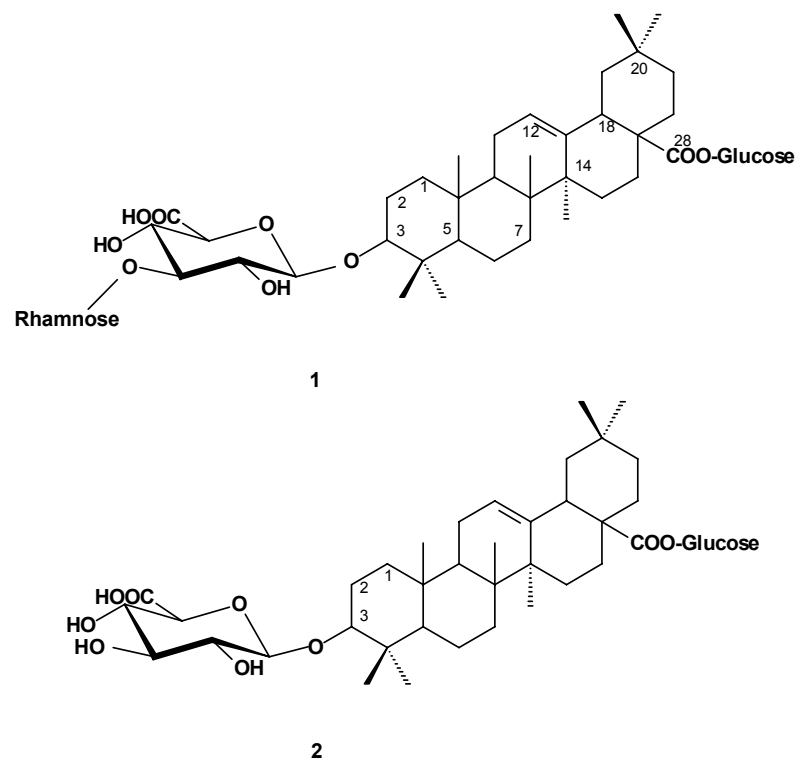

Fig. 2: structures of saponins $\mathbf{1}$ and $\mathbf{2}$ isolated from Mixture $C$

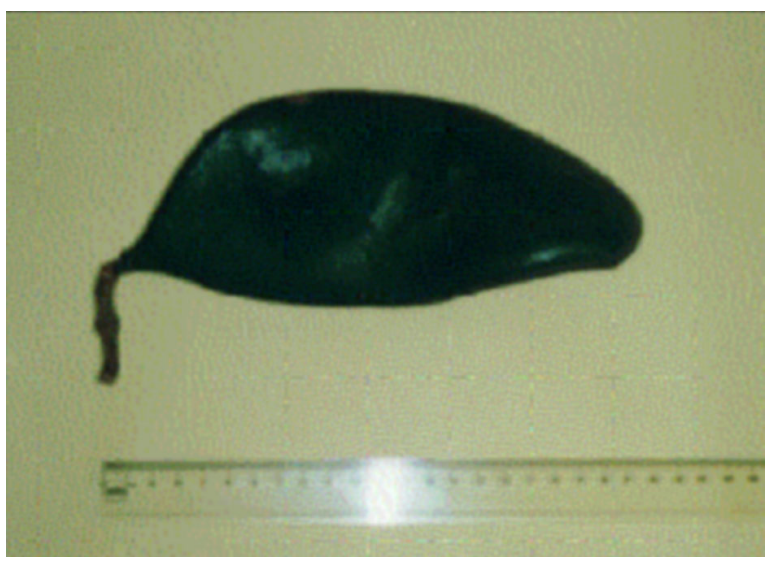

Fig. 3: fruit of Swartzia langsdorffii

\section{DISCUSSION}

The aerial parts, leaves, seeds and fruits (Fig. 3) are of special relevance because they can provide a larger amount of plant material with minimal damage to the plant, as they are renewable.

The test of persistent foam in dilute acid solution proved that the seeds and fruits of $S$. langsdorffii were rich in saponins (Table III). All the samples tested showed a significant molluscicidal activity against $B$. glabrata adults (see Table IV). None of the samples containing saponins was active against the egg-masses. This inactivity might be due to the high molar mass of the saponins that could prevent penetration into the egg-mass membranes. Sample Mixture $B_{1}$ displayed a very good result for eggs but it was shown not to have saponins by the foam test (Tables III, IV).

Both seeds and fruits were very rich in saponins, but the fruits were also rich in sugars, which can interfere in the saponin isolation. The seeds, especially the arils, had the greater molluscicidal potential for the following reasons: (a) the aril had more than $5 \% \mathrm{w} / \mathrm{w}$ in saponin content; (b) the saponin mixture isolated from the aril was

\section{TABLE III}

Molluscicidal activity in $24 \mathrm{~h}$ expressed in $50 \%$ lethal concentration $\left(\mathrm{LC}_{50}\right)$ in $\mu \mathrm{g} / \mathrm{ml}$

\begin{tabular}{lcc}
\hline Samples & Adults & Eggs \\
\hline Leaves $^{a}(\mathrm{EtOH})$ & 95 & NT \\
Roots $^{a}(\mathrm{MeOH})$ & 100 & NT \\
Fruits $^{a}(\mathrm{MeOH})$ & 33.59 & - \\
Seeds $^{a}(\mathrm{EtOH})$ & 100 & - \\
Seed mixture $B_{l}{ }^{b}$ & 6 & 9.5 \\
Seed saponin mixture $B_{2}{ }^{b}$ & 100 & - \\
Aril saponin mixture $D^{b}$ & 100 & -
\end{tabular}

$a$ : crude extract; $b$ : isolated saponin mixture; NT: not tested; -: negative $=$ no activity observed at this concentration

TABLE IV

Saponin aglycone NMR $\delta_{\mathrm{H}}$ and $\delta_{\mathrm{C}}$ in pyridine- $d_{5}$ obtained for Mixtures $A$ and $C$

\begin{tabular}{|c|c|c|c|c|c|}
\hline Carbon $^{a}$ & $\delta_{\mathrm{H}}$ & $\delta_{\mathrm{C}}$ & Carbon $^{a}$ & $\delta_{\mathrm{H}}$ & $\delta_{\mathrm{C}}$ \\
\hline $\mathrm{CH}_{2}-1$ & $0.78 \mathrm{~m} ; 1.32 \mathrm{~m}$ & 38.5 & $\mathrm{CH}_{2}-16$ & $1.88 \mathrm{~m} ; 0.90 \mathrm{~m}$ & 23.6 \\
\hline $\mathrm{CH}_{2}^{2}-2$ & $1.76 \mathrm{~m} ; 2.20 \mathrm{~m}$ & 26.0 & $\mathrm{C}_{0}-17$ & - & 46.9 \\
\hline $\mathrm{CH}-3$ & $3.25 d l$ & 88.9 & CH-18 & $3.18 d d$ & 41.6 \\
\hline $\mathrm{C}_{0}-4$ & - & 39.3 & $\mathrm{CH}_{2}-19$ & $1.25 \mathrm{~m} ; 1.75 \mathrm{~m}$ & 46.1 \\
\hline $\mathrm{CH}-5$ & $0.75 \mathrm{~m}$ & 55.6 & $\mathrm{C}_{0}-20$ & - & 30.0 \\
\hline $\mathrm{CH}_{2}-6$ & $1.26 \mathrm{~m} ; 1.45 \mathrm{~m}$ & 18.1 & $\mathrm{CH}_{2}-21$ & $1.50 \mathrm{~m} ; 1.00 \mathrm{~m}$ & 32.9 \\
\hline $\mathrm{CH}_{2}-7$ & $1.74 m ; 1.82$ & 32.4 & $\mathrm{CH}_{2}-22$ & $0.86 \mathrm{~m} ; 0.95 \mathrm{~m}$ & 32.9 \\
\hline $\mathrm{C}_{0}-8$ & - & 39.8 & $\mathrm{CH}_{3}-23$ & $1.20 \mathrm{~s}$ & 28.0 \\
\hline $\mathrm{CH}-9$ & $1.52 \mathrm{~m}$ & 47.8 & $\mathrm{CH}_{3}-24$ & $0.92 s$ & 16.9 \\
\hline $\mathrm{C}_{0}-10$ & - & 36.8 & $\mathrm{CH}_{3}-25$ & $0.82 s$ & 15.4 \\
\hline $\mathrm{CH}_{2}-11$ & $1.96 \mathrm{~m} ; 2.10 \mathrm{~m}$ & 23.9 & $\mathrm{CH}_{3}-26$ & $1.05 s$ & 17.3 \\
\hline $\mathrm{CH}-12$ & $5.44 \mathrm{sl}$ & 122.8 & $\mathrm{CH}_{3}-27$ & $1.30 \mathrm{~s}$ & 26.0 \\
\hline$C_{0}-13$ & - & 144.0 & $\mathrm{C}_{0}-28$ & - & 176.4 \\
\hline $\mathrm{C}_{0}-14$ & - & 42.0 & $\mathrm{CH}_{3}-29$ & $1.36 s$ & 33.2 \\
\hline $\mathrm{CH}_{2}-15$ & $1.25 \mathrm{~m} ; 2.34 \mathrm{~m}$ & 28.0 & $\mathrm{CH}_{3}-30$ & $0.90 s$ & 23.4 \\
\hline
\end{tabular}

$a$ : all the assignments were made by a combination of DEPT, ${ }^{13} \mathrm{C}-\mathrm{NMR}$ spectrum and $2 \mathrm{D}-\mathrm{NMR}$ experiments: ${ }^{1} \mathrm{H}-{ }^{1} \mathrm{H}$ two-dimensional correlation spectroscopy, nuclear Overhauser and exchange spectroscopy, heteronuclear multiple quantum coherence, and heteronuclear multiple-bond connectivity experiments 
inactive against $A$. salina, suggesting inactivity against non-targeted organisms; (c) the aril is a renewable part of the plant.

The 2D-NMR spectral data showed that all saponins of S. langsdorffii have the same oleanolic acid aglycone. The chemical shifts of the aglycone carbons correspond to those observed for saponins isolated from S. simplex and $S$. schomburgkii, and to other related saponins (Zhang et al. 2000).

Table V shows the data obtained in pyridine for the aglycones of the saponins of Mixture $C$ (seeds) and $A$ (fruits). Table VI shows the data (in $\mathrm{CD}_{3} \mathrm{OD}$ ) for the aglycones of the saponins from Mixtures $B_{2}, C$ and $D$. Concerning the sugars moieties, saponins $\mathbf{1}$ and $\mathbf{2}$ have a glucuronic acid attached to carbon C-3 and were previously isolated from $S$. simplex. These saponins were identified by the analysis of mass, ${ }^{1} \mathrm{H}-\mathrm{NMR}$ and ${ }^{13} \mathrm{C}-\mathrm{NMR}$ spectral data obtained for Mixture $C$. The electron spray impact mass spectrum (ESI-MS) exhibited two molecular ions at $m / z 940$ and $m / z$ 793. The ${ }^{13} \mathrm{C}$-NMR spectrum gave evidence that oleanolic acid was substituted at C-3 and $\mathrm{C}-28$. The ${ }^{13} \mathrm{C}-\mathrm{NMR}$ spectrum showed that aglycone carbon $\mathrm{C}-3$ had two signals, indicating that the saponin structures differed only by the sugars attached to carbon $\mathrm{C}$-3. All the other ${ }^{13} \mathrm{C}$-NMR signals were common to both saponins. This was further confirmed by ${ }^{13} \mathrm{C}$-NMR carbon signals corresponding to a terminal glucose at C- $28\left(\delta_{\mathrm{C}}\right.$ $95.6 ; 74.0 ; 78.6 ; 70.9 ; 79.2$ e 62.0$)$, which appeared larger

TABLE V

Saponin aglycone NMR $\delta_{\mathrm{H}}$ and $\delta_{\mathrm{C}}$ in $\mathrm{CD}_{3} \mathrm{OD}$ obtained for Mixtures $B_{2}, C$ and $D$

\begin{tabular}{|c|c|c|c|c|c|}
\hline Carbon $^{a}$ & $\delta_{\mathrm{C}}$ & $\delta_{\mathrm{H}}$ & Carbon $^{a}$ & $\delta_{\mathrm{C}}$ & $\delta_{\mathrm{H}}$ \\
\hline $\mathrm{CH}_{2}-1$ & 39.8 & $0.87 d ; 1.48 m$ & $\mathrm{CH}_{2}-16$ & & $1.78 \mathrm{~m} ; 1.48 \mathrm{~m}$ \\
\hline $\mathrm{CH}_{2}^{2}-2$ & 27.0 & $0.98 \mathrm{~s} ; 1.54 \mathrm{~m}$ & $\mathrm{C}_{0}-17$ & 48.0 & \\
\hline $\mathrm{CH}-3$ & 90.6 & $3.10 \mathrm{dl}$ & CH-18 & 42.5 & $2.75 d d$ \\
\hline $\mathrm{C}_{0}-4$ & 37.9 & & $\mathrm{CH}_{2}-19$ & 47.5 & $1.1 \mathrm{~m} ; 1.5 \mathrm{~m}$ \\
\hline $\mathrm{CH}-5$ & 57.0 & 0.7 & & & \\
\hline $\mathrm{CH}_{2}-6$ & 19.3 & $1.27 \mathrm{~m} ; 1.44 \mathrm{~m}$ & $\mathrm{C}_{0}-20$ & 31.6 & \\
\hline $\mathrm{CH}_{2}^{2}-7$ & 33.0 & $1.49 \mathrm{~m} ; 1.62 \mathrm{~m}$ & $\mathrm{CH}_{2}-21$ & 34.8 & $1.1 \mathrm{~m} ; 1.3 \mathrm{~m}$ \\
\hline $\mathrm{C}_{0}-\frac{2}{8}$ & 40.19 & & $\mathrm{CH}_{2}-22$ & 33.8 & $1.21 \mathrm{~m} ; 1.37 \mathrm{~m}$ \\
\hline $\mathrm{CH}-9$ & 48.0 & $1.5 \mathrm{~m}$ & $\mathrm{CH}_{3}-23$ & 28.4 & $0.98 s$ \\
\hline $\mathrm{C}_{0}-10$ & 38.5 & & $\mathrm{CH}_{3}-24$ & 17.8 & $0.69 s$ \\
\hline $\mathrm{CH}_{2}-11$ & 24.0 & $1.6 \mathrm{~m} ; 1.92 \mathrm{~m}$ & $\mathrm{CH}_{3}-25$ & 17.0 & $0.75 s$ \\
\hline $\mathrm{CH}-12$ & 123.5 & $5.15 \mathrm{sl}$ & $\mathrm{CH}_{3}-26$ & 16.2 & $0.85 s$ \\
\hline$C_{0}-13$ & 144.0 & & $\mathrm{CH}_{3}-27$ & 26.2 & $1.08 s$ \\
\hline $\mathrm{C}_{0}-14$ & 40.7 & & $\mathrm{C}_{0}-28$ & 178.3 & \\
\hline \multirow{2}{*}{$\mathrm{CH}_{2}-15$} & 29.0 & $0.94 \mathrm{~m} ; 1.69 \mathrm{~m}$ & $\mathrm{CH}_{3}-29$ & 33.6 & $0.83 s$ \\
\hline & & & $\mathrm{CH}_{3}-30$ & 24.0 & $0.85 s$ \\
\hline
\end{tabular}

$a$ : all the assignments were made by a combination of DEPT, ${ }^{13} \mathrm{C}-\mathrm{NMR}$ spectrum and 2D-NMR experiments: ${ }^{1} \mathrm{H}-{ }^{1} \mathrm{H}$ two-dimensional correlation spectroscopy, nuclear Overhauser and exchange spectroscopy, heteronuclear multiple quantum coherence, and heteronuclear multiple-bond connectivity experiments

TABLE VI

NMR $\delta_{\mathrm{H}}$ and $\delta_{\mathrm{C}}$ in pyridine- $d_{5}$ and $\mathrm{CD}_{3} \mathrm{OD}$ observed in 2D-HSQC for the signals of the sugars of the major saponin (1) from Mixture $C$ isolated from the seed

\begin{tabular}{|c|c|c|c|c|c|}
\hline Saponin 1 & \# & $\delta_{\mathrm{C}}$ (pyridine) & $\delta_{\mathrm{H}}($ pyridine $)$ & $\delta_{\mathrm{C}}\left(\mathrm{CD}_{3} \mathrm{OD}\right)$ & $\delta_{\mathrm{H}}\left(\mathrm{CD}_{3} \mathrm{OD}\right)$ \\
\hline \multirow[t]{6}{*}{ Glucose-28 } & $1 "$ & 95.61 & 6.35 & 95.7 & 5.25 \\
\hline & $2 "$ & 74.0 & 4.22 & 73.9 & 3.28 \\
\hline & $3 "$ & 78.6 & 4.27 & 78.3 & 3.34 \\
\hline & $4 "$ & 70.92 & 4.34 & 71.1 & 3.31 \\
\hline & $5 "$ & 79.18 & 4.02 & 78.7 & 3.25 \\
\hline & 6" & 62.2 & $4.33 ; 4.44$ & 62.4 & $3.39 ; 3.41$ \\
\hline \multirow[t]{6}{*}{ Glucuronic acid } & 1 , & 106.5 & 4.75 & 106.2 & 4.27 \\
\hline & 2 & 75.6 & 3.98 & 75.4 & 3.22 \\
\hline & 3, & 81.8 & 4.37 & 84.0 & 3.47 \\
\hline & 4 ' & 71.8 & 4.22 & 71.1 & 3.22 \\
\hline & 5, & 78.7 & 4.02 & 76.0 & 3.17 \\
\hline & 6, & 173.3 & & & \\
\hline \multirow[t]{6}{*}{ Rhamnose-3' } & $1 "$, & 102.3 & 6.28 & 102.5 & 5.15 \\
\hline & $2 "$, & 72.4 & 4.7 & 72.4 & 3.86 \\
\hline & $3 "$, & 72.3 & 4.58 & 72.4 & 3.63 \\
\hline & $4 "$, & 74.2 & 4.28 & 74.4 & 3.30 \\
\hline & $5 "$, & 69.5 & 5.05 & 69.9 & 3.98 \\
\hline & $6 " ”$ & 18.6 & 1.7 & 18.0 & 1.7 \\
\hline
\end{tabular}


TABLE VII

NMR $\delta_{\mathrm{H}}$ and $\delta_{\mathrm{C}}$ in pyridine- $d_{5}$ and $\mathrm{CD}_{3} \mathrm{OD}$ observed in the 2D-HSQC for the signals of sugars of the minor saponin (2) of the Mixture $C$ isolated from the seeds

\begin{tabular}{|c|c|c|c|c|c|}
\hline Saponin 2 & \# & $\delta_{\mathrm{C}}($ pyridine $)$ & $\delta_{\mathrm{H}}($ pyridine $)$ & $\delta_{\mathrm{C}}\left(\mathrm{CD}_{3} \mathrm{OD}\right)$ & $\delta_{\mathrm{H}}\left(\mathrm{CD}_{3} \mathrm{OD}\right)$ \\
\hline \multirow[t]{6}{*}{ Glucose-28 } & 1 & 95.6 & 6.35 & 95.7 & 5.4 \\
\hline & 2 & 74.0 & 4.22 & 73.9 & 3.23 \\
\hline & 3 & 78.6 & 4.27 & 78.3 & 3.34 \\
\hline & 4 & 70.9 & 4.34 & 71.1 & 3.31 \\
\hline & 5 & 79.2 & 4.02 & 78.7 & 3.25 \\
\hline & 6 & 62.0 & $4.42 ; 4.46$ & 62.4 & $3.39 ; 3.41$ \\
\hline \multirow[t]{6}{*}{ Glucuronic acid } & 1 & 105.2 & 4.75 & 106.3 & 4.27 \\
\hline & 2 & 75.0 & 3.96 & 75.7 & 3.96 \\
\hline & 3 & 78.0 & 4.15 & 78.2 & 3.60 \\
\hline & 4 & 73.7 & 4.17 & 71.4 & 3.22 \\
\hline & 5 & 76.2 & 4.31 & 77.6 & 3.17 \\
\hline & 6 & 173.3 & & 173.3 & \\
\hline
\end{tabular}

than the signals from other sugars. The MS/MS experiment, selecting ion $\mathrm{m} / \mathrm{z} 940$, revealed signals at $\mathrm{m} / \mathrm{z}$ $777\left[\mathrm{M}^{+}-\mathrm{H}-162\right]^{-}, m / z 631\left[\mathrm{M}^{+}-\mathrm{H}-162\right.$ - 146] ${ }^{-}$and $m / z$ $455\left[\mathrm{M}^{+}-\mathrm{H}-162-146-176\right]^{-}$, that indicated a glucosyl, a rhamnosyl and a glucuronic acid moieties for saponin $\mathbf{1}$.

Based on spectral data of the saponins isolated from S. simplex and S. schomburgkii saponin 1 was identified as $\beta$-D-glycopyranosyl[ $\alpha$-L-rhamnopyranosyl- $(1 \rightarrow 3)-\beta$ D-glucuronopyranosyl-( $1 \rightarrow 3)]$-3 $\beta$-hydroxyolean-12-ene28-oate (Table VII , Fig. 2).

Analogously, the MS/MS experiment selecting ion $m / z 793$ revealed signals at $m / z 631\left[\mathrm{M}^{+}{ }^{+} \mathrm{H}-162\right]^{-}$and at $m / z 455\left[^{\mathrm{M}^{+}}{ }^{-} \mathrm{H}-162-176\right]^{-}$that indicated a glucosyl and a glucuronic acid moieties for saponin 2. Saponin 2 was therefore identified as $\beta$-D-glucopyranosyl- $(1 \rightarrow 3)-\beta-D-$ glucuronopyranosyl- $(1 \rightarrow 3)]$-3 $\beta$-hydroxyolean-12-ene-28oate, also isolated from $S$. simplex (Table VIII, Fig. 2).

The less polar saponins (retention times: 12.2, 12.4 and $14.2 \mathrm{~min}$ ) of Mixtures $A_{2}, B_{2}$ and $D$, may be similar to those isolated from $S$. schomburgkii (Abdel-Kader et al. 2000), which had a glucose attached at carbon C-3. The DEPT spectra of these mixtures had at least four signals of $\mathrm{CH}_{2}$ glucose groups around $\delta_{\mathrm{C}} 62-64$, suggesting the presence of other glucose units.

Concerning to the chemotaxonomic significance, the occurrence of triterpenoidal saponins with molluscicidal activity in $S$. langsdorffii shows that it is more related to the species of Swartzia sect. Possira, specifically to $S$. simplex suggesting the transfer of $S$. langsdorffii from the section Swartzia to the section Possira.

\section{ACKNOWLEDGMENTS}

To Lenita de Freitas Tallarico from the Parasitology Department of the Butantan Institute of São Paulo University, São Paulo, Brazil, for the fruit molluscicidal tests. To the Agronomic Institute of Campinas, SP, Brazil, for authorizing the collection of the plant parts. To Dr Carol Collins for critically reading this paper.

\section{REFERENCES}

Abdel-Kader MS, Bahler BD, Malone S, Werkhoven MCM, Wisse JH, Neddermann KM, Bursuker I, Kingston DGI
2000. Bioactive saponins from Swartzia schomburgkii from the Suriname Rainforest. J Nat Prod 63: 1461-1464.

Borel C, Hostettmann K 1987. Molluscicidal saponins from Swartzia madagascariensis Desvaux. Helv Chim Acta 70: 571-576.

Borel C, Gupta MP, Hostettmann K 1987. Molluscicidal saponins from Swartzia simplex. Phytochemistry 26: 26852689.

Clark TE, Appleton, CC, Drewe, SE 1997. A semi-quantitative approach to the selection of appropriate candidate plant molluscicides - a South African application. J Ethnopharmacol 56: 1-13.

Finney DJ 1962. Probit Analysis, Cambridge University Press, Cambridge.

Hostettmann, KE, Wolfender, JL 1997. The search for biologically active secondary metabolites. Pest Sci 51: 471-482.

Kawano T, Okazaki K, Ré L 1992. Embryonic development of Biomphalaria glabrata (Say, 1818) (Mollusca, Gastropoda, Planorbidae): A practical guide to the main stages. Malacologia 34: 25-32.

Kirkbride, JH, Wiersema JH 1997. Bobgunnia, a new African genus of tribe Swartzieae (Fabaceae, Faboideae). Brittonia 49: 1-23.

Mansano, VF, Tozzi, AMGA. 1999. The taxonomy of some Swartzieae (Leguminosae, Subfam. Papilionoideae) from Southeastern Brazil. Brittonia 51: 149-158.

McLaughlin JL, Rogers LL, Anderson JE 1998. The use of biological assays to evaluate botanicals. Drug Informat $J$ 32: 513-524.

Okazaki K, Andrade Junior HF, Kawano T 1996. Effect of $60 \mathrm{Co}$ gamma radiation on Biomphalaria glabrata (Mollusca, Gastropoda) embryos: mortality, malformation and hatching. Braz J Med Biol Res 29:1057-1067.

Schenkel EP 1999. Saponinas. In CMO Simões, Farmacognosia: da Planta ao Medicamento, Universidade UFRGS/ UFSC, Porto Alegre/Florianópolis, 604 pp.

Suter R, Tanner M, Borel C, Hostettmann K, Freyvogel TA 1986. Laboratory and field trials at Ifakara (Kilombero District, Tanzania) on the plant molluscicide Swartziamadagascariensis. Acta Trop 43: 69-83.

Zhang Z, Koike K, Jia Z, Nikaido T, Guo D, Zheng J 1999. Triterpenoidal saponins from Gleditsia sinensis. Phytochemistry 52: 715-722. 